\title{
Versatile use of dermal substitutes: A retrospective survey of 127 consecutive cases
}

\author{
Giovanni Nicoletti ${ }^{1,2}$, Marco Mario Tresoldi ${ }^{1,2}$, Alberto Malovini $^{3}$, Marco Visaggio ${ }^{1}$, Angela Faga ${ }^{4,5}$, \\ Silvia Scevola ${ }^{2}$ \\ ${ }^{1}$ Department of Clinical Surgical Diagnostic and Pediatric Sciences, Plastic and Reconstructive Surgery Unit, University of \\ Pavia, ${ }^{2}$ Advanced Technologies for Regenerative Medicine and Inductive Surgery Research Center, University of Pavia, \\ ${ }^{3}$ Laboratory of Informatics and Systems Engineering for Clinical Research, Maugeri Clinical Scientific Institutes, ${ }^{4}$ Plastic and \\ Reconstructive Surgery Unit, Maugeri Clinical Scientific Institutes, ${ }^{5}$ Department of Molecular Medicine, University of Pavia, \\ Pavia, Italy
}

Address for correspondence: Dr. Giovanni Nicoletti, Department of Clinical Surgical Diagnostic and Pediatric Sciences, Plastic and Reconstructive Surgery Unit, University of Pavia, Viale Brambilla, 74, 27100 Pavia, Italy. E-mail: giovanni.nicoletti@unipv.it

\section{ABSTRACT}

Background: Dermal substitutes are currently largely used for the treatment of huge skin loss in patients in critical general health conditions, for the treatment of severe burns and to promote the healing process in chronic wounds. Aims: The authors performed a retrospective assessment of their experience with bioengineered skin to possibly identify the most appropriate clinical indication and management for each substitute. Materials and Methods: The study involved 109 patients with 127 skin defects repaired with dermal substitutes over a 9 years period, from 2007 to 2016. Hyalomatrix ${ }^{\circledR}$ was used in 63 defects, whereas Integra ${ }^{\circledR}$ and Nevelia ${ }^{\circledR}$ were used in 56 and 8 defects, respectively. Results: The statistical analysis failed to reveal a correlation between the choice of a specific dermal substitute and any possible clinical variable except in the soft-tissue defects of the scalp where Hyalomatrix ${ }^{\circledR}$ was electively used. Conclusions: In the authors' experience, the scalp defects followed a radical excision of skin tumours that included the periosteum. Here, the preliminary cover with a hyaluronan three-dimensional scaffold constantly allowed for the regeneration of a derma-like layer with a rich vascular network fit for supporting a split-thickness skin graft. Nevertheless, the authors still prefer Integra ${ }^{\circledR}$ when the goal is a better cosmetic outcome and Hyalomatrix ${ }^{\circledR}$ when a faster wound healing is required, especially in the management of deep wounds where the priority is a fast obliteration with a newly formed tissue with a rich blood supply. However, these clinical indications still are anecdotally based.

\section{KEY WORDS}

Clinical application; collagen; dermal substitutes; hyaluronan; skin reconstruction

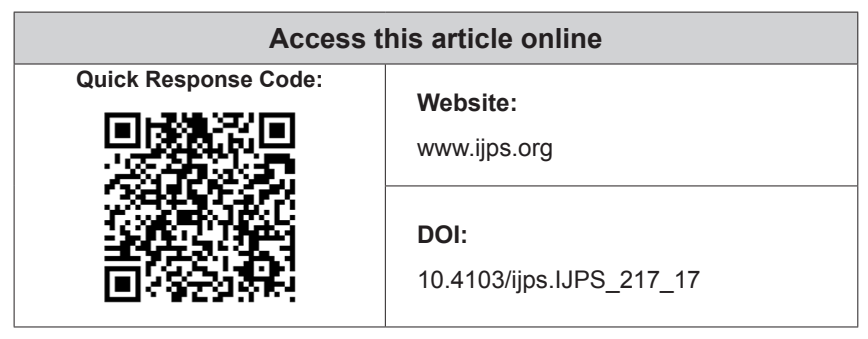

This is an open access journal, and articles are distributed under the terms of the Creative Commons Attribution-NonCommercial-ShareAlike 4.0 License, which allows others to remix, tweak, and build upon the work non-commercially, as long as appropriate credit is given and the new creations are licensed under the identical terms.

For reprints contact: reprints@medknow.com

How to cite this article: Nicoletti G, Tresoldi MM, Malovini A, Visaggio M, Faga A, Scevola S. Versatile use of dermal substitutes: A retrospective survey of 127 consecutive cases. Indian J Plast Surg 2018;51:46-53. 


\section{INTRODUCTION}

( ermal substitutes are currently largely used for the treatment of huge skin loss in patients in critical general health conditions, ${ }^{[1,2]}$ for the treatment of severe burns ${ }^{[3-5]}$ and to promote the healing process in chronic wounds. ${ }^{[6]}$

In our clinical practice, the most frequently used dermal substitutes are Integra ${ }^{\circledR}$ (Integra LifeSciences, Plainsboro, NJ, USA), Hyalomatrix ${ }^{\circledR}$ (Anika Therapeutics, Bedford, MA, USA) and more recently, Nevelia ${ }^{\circledR}$ (SYMATESE Biomateriaux, ZI Les Troques, Chaponost, France), as well.

The choice among the different substitutes was originally made according to their reputation for popularity, reliability, availability and cost convenience. Subsequently, as our learning curve progressed to a stage of established clinical confidence, the use of bioengineered skin was extended to several innovative indications and currently, it has replaced the traditional indications for flap surgery for both functional and aesthetic indications in an increasing number of cases, too..$^{[7-9]}$

In a patients' cohort of ours, we already performed an observational study to assess the clinical and histological long-term outcomes of Hyalomatrix ${ }^{\circledR[8]}$ used for revision of retracting scars; similarly, we also carried out a long-term objective in vivo instrumental assessment of the skin properties after reconstruction with either Integra ${ }^{\circledR}$ or Hyalomatrix ${ }^{\circledR} \cdot{ }^{9]}$

In the present study, we performed a retrospective assessment of the whole of our experience with bioengineered skin and a comprehensive overview of our evidence-based clinical indications. The aim of the survey was an attempt at possibly identify the most appropriate clinical indication and management for each substitute.

\section{MATERIALS AND METHODS}

The study was carried at the Plastic Surgery Unit, University of Pavia, Salvatore Maugeri Clinical Scientific Institutes and involved 109 patients, 59 females and 68 males, with an average age of 70 years (range 11-93).

The skin defect was considered the experimental unit of the study irrespective of the number of defects per patient. An overall of 127 skin defects were repaired with bioengineered skin over a period 9 years, from 2007 to 2016.

Analysed data included patients' sex and age, type of dermal substitute, anatomical sites, wound aetiology, skin loss area and depth, the time interval between the application of the substitute and its coverage with a skin graft, the time interval between the skin graft application and the complete clinical healing of the defect.

The anatomical sites were grouped into five main areas: lower limb including the foot, upper limb including hand and axilla, face and neck, scalp and trunk including the gluteal region.

The area of each soft tissue loss was calculated using the ImageJ software, and its depth was routinely measured intraoperatively with a ruler.

\section{Statistical methods}

Categorical variables' distribution was described by counts and frequencies. Since quantitative variables' distribution deviated from the normality assumptions (based on the visual inspection of quantilequantile plots), they were described by median $\left[25^{\text {th }}\right.$ $75^{\text {th }}$ percentiles, interquartile range $\left.(I Q R)\right]$. The presence of statistically significant differences in terms of categorical variables' distribution between substitutes' types was assessed using the Fisher's exact test; while the Kruskal-Wallis test and Wilcoxon Rank Sum test were employed to test for the presence of statistically significant differences in terms of quantitative variables between substitutes' types as appropriate. The significance threshold was set to $P<0.05$. Statistical analyses were performed using the R software version 3.3.0 (www.r-project.org, Free Software Foundation, Boston, MA, USA).

\section{RESULTS}

Hyalomatrix ${ }^{\circledR}$ was used in 63 defects, while Integra ${ }^{\circledR}$ and Nevelia ${ }^{\circledR}$ were used in 56 and 8 defects, respectively.

The distribution of the bioengineered skin repair per anatomical site was:

- Lower limb including the foot: 27

- Upper limb including hand and axilla: 20

- Face and neck: 44 
- Scalp: 27

- Trunk including the gluteal region: 9.

The reported aetiologies of the skin defects were as follows: difficult to heal wounds (25), excision of skin tumours (87) and surgical revision of contractures and scars (15).

The characteristics of the analysed samples are summarised in Table 1.

The dermal substitutes demonstrated a trend for progressively increasing frequency of use along the period of study [Figure 1].

The characteristics of the analysed samples by substitutes' type are depicted in Table 2.

\section{Table 1: Characteristics of the analysed samples}

\begin{tabular}{|c|c|c|}
\hline Variable & Level & Distribution \\
\hline \multirow[t]{2}{*}{ Sex } & M & $68(53.54 \%)$ \\
\hline & $\mathrm{F}$ & $59(46.46 \%)$ \\
\hline Age & Years & $70(50-82)$ \\
\hline \multirow[t]{3}{*}{ Dermal substitute } & Integra ${ }^{\circledR}$ & $56(44.09 \%)$ \\
\hline & Hyalomatrix $^{\circledR}$ & $63(49.61 \%)$ \\
\hline & Nevelia $^{\circledR}$ & $8(6.3 \%)$ \\
\hline \multirow[t]{5}{*}{ Site } & Lower limb & $27(21.26 \%)$ \\
\hline & Upper limb & $20(15.75 \%)$ \\
\hline & Face and neck & $44(34.65 \%)$ \\
\hline & Scalp & $27(21.26 \%)$ \\
\hline & Trunk & $9(7.09 \%)$ \\
\hline \multirow[t]{3}{*}{ Aetiology } & $\begin{array}{l}\text { Difficult-to-heal } \\
\text { wounds }\end{array}$ & $25(19.69 \%)$ \\
\hline & Skin tumors & $87(68.5 \%)$ \\
\hline & Retracting scars & $15(11.81 \%)$ \\
\hline $\begin{array}{l}\text { Skin graft time after } \\
\text { substitute application }\end{array}$ & Days & $28(26.5-40)$ \\
\hline Skin graft engraftment time & Days & $14(14-21)$ \\
\hline Wound depth & $\mathrm{Cm}$ & $0.5(0.5-1)$ \\
\hline Wound area & $\mathrm{Cm}^{2}$ & $19.25(8-41.62)$ \\
\hline
\end{tabular}

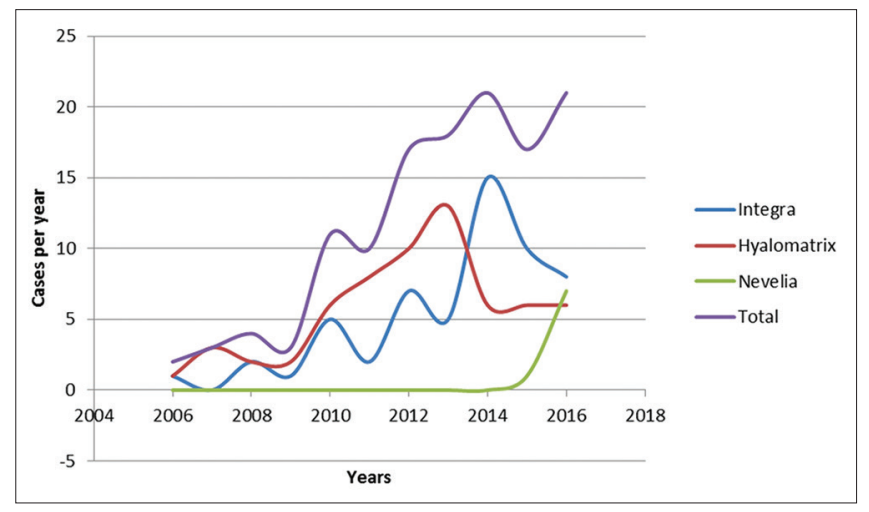

Figure 1: Trend for the clinical use of the different dermal substitutes along the period of study
Results showed that the median age of individuals whose skin defects were treated by Nevelia ${ }^{\circledR}$ was significantly higher than that of those whose defects were treated by Integra $^{\circledR}$ (Median $=75.5, \mathrm{IQR}=73.5-82.5$ vs. Median $=65.5, \mathrm{IQR}=38.5-77.25, P=0.031)$.

The skin defects of the scalp were significantly more frequently treated by Hyalomatrix ${ }^{\circledR}$ compared to Integra ${ }^{\circledR}(31.75 \%$ vs. $12.5 \%, P=0.016)$.

No other statistically significant differences were observed.

\section{DISCUSSION}

A broad age range was observed in our sample. We tended to use the bioengineered skin for the correction of scar contractures in patients in the stage of development to both save more complex reconstructive options for later stages and to limit the overall burden of surgical scars [Figure 2]. In the cosmetically demanding young patients, we also used the bioengineered skin for the reconstruction of defects of the face as an alternative to traditional skin flaps to minimise the amount of visible scars [Figure 3]. Nevertheless, the vast majority of our sample included elderly patients suffering from advanced skin cancers that are far more frequent in this age group. In our experience, bioengineered skin progressively became the gold standard for reconstruction of skin defects in the aged patients as the comorbidities frequently reported in this patient cohort generally contraindicate complex surgical procedures. Regenerative surgery,

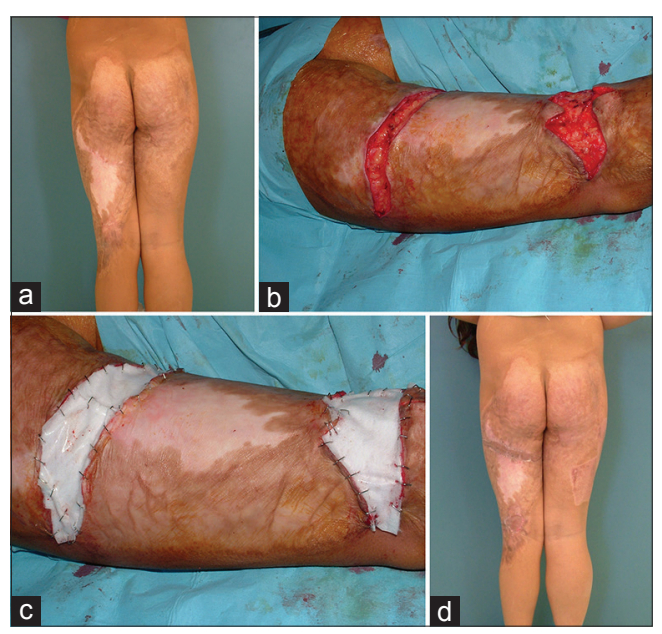

Figure 2: (a) Retracting post-burn scars in the posterior aspect of the left lower limb. (b) Soft tissue loss following scar release in the lower left gluteal area and in the left popliteal fossa. (c) The defects are temporarily repaired with Hyalomatrix ${ }^{\circledR}$ dermal substitute. (d) Stable repair with split thickness skin grafts 
Table 2: Samples' characteristics by dermal substitute type

\begin{tabular}{|c|c|c|c|c|c|c|c|c|}
\hline \multirow[b]{2}{*}{ Variable } & \multirow[b]{2}{*}{ Level } & \multicolumn{3}{|c|}{ Distributions [count (\%) or median (IQR)] } & \multicolumn{4}{|c|}{ Comparisons (p-value) } \\
\hline & & $\begin{array}{c}\text { Integra }^{\circledR} \\
(56)\end{array}$ & $\begin{array}{c}\text { Hyalomatrix }^{\circledR} \\
\text { (63) }\end{array}$ & $\begin{array}{l}\text { Nevelia }^{\circledR} \\
\text { (8) }\end{array}$ & Global & $\begin{array}{c}\text { Integra }^{\circledR} \\
\text { vs. } \\
\text { Hyalomatrix }^{\circledR} \\
\end{array}$ & $\begin{array}{c}\text { Integra }^{\circledR} \\
\text { vs. } \\
\text { Nevelia }^{\circledR} \\
\end{array}$ & $\begin{array}{c}\text { Hyalomatrix }^{\circledR} \\
\text { vs. } \\
\text { Nevelia }^{\circledR} \\
\end{array}$ \\
\hline \multirow[t]{3}{*}{ Sex } & & & & & 0.560 & 0.362 & 0.708 & 1 \\
\hline & M & $27(48.21 \%)$ & $36(57.14 \%)$ & $5(62.5 \%)$ & & & & \\
\hline & $\mathrm{F}$ & $29(51.79 \%)$ & $27(42.86 \%)$ & $3(37.5 \%)$ & & & & \\
\hline \multicolumn{9}{|l|}{ Age } \\
\hline & Years & $\begin{array}{c}65.5 \\
(38.5-77.25)\end{array}$ & $73(57.5-82.5)$ & $\begin{array}{c}75.5 \\
(73.5-82.5)\end{array}$ & $0.037^{*}$ & 0.066 & $0.031^{*}$ & 0.187 \\
\hline \multirow[t]{6}{*}{ Site } & & & & & 0.072 & 0.090 & 0.481 & 0.094 \\
\hline & Lower limb & $11(19.64 \%)$ & $14(22.22 \%)$ & $2(25 \%)$ & 0.835 & 0.823 & 0.660 & 1 \\
\hline & Upper limb & $12(21.43 \%)$ & $7(11.11 \%)$ & $1(12.5 \%)$ & 0.324 & 0.140 & 1 & 1 \\
\hline & Face and neck & $22(39.29 \%)$ & 19 (30.16\%) & $3(37.5 \%)$ & 0.552 & 0.337 & 1 & 0.696 \\
\hline & Scalp & $7(12.5 \%)$ & $20(31.75 \%)$ & $0(0 \%)$ & $0.013^{*}$ & $0.016^{*}$ & 0.582 & 0.095 \\
\hline & Trunk & $4(7.14 \%)$ & $3(4.76 \%)$ & $2(25 \%)$ & 0.116 & 0.705 & 0.159 & 0.094 \\
\hline \multirow[t]{4}{*}{ Aetiology } & & & & & 0.604 & 0.412 & 1 & 0.628 \\
\hline & $\begin{array}{l}\text { Difficult-to-heal } \\
\text { wounds }\end{array}$ & $9(16.07 \%)$ & $15(23.81 \%)$ & $1(12.5 \%)$ & 0.587 & 0.323 & 1 & 0.673 \\
\hline & Skin tumors & $41(73.21 \%)$ & 39 (61.9\%) & $7(87.5 \%)$ & 0.239 & 0.241 & 0.667 & 0.246 \\
\hline & $\begin{array}{l}\text { Retracting } \\
\text { scars }\end{array}$ & $6(10.71 \%)$ & $9(14.29 \%)$ & $0(0 \%)$ & 0.615 & 0.593 & 1 & 0.584 \\
\hline \multicolumn{9}{|c|}{$\begin{array}{l}\text { Skin graft time after } \\
\text { substitute application }\end{array}$} \\
\hline & Days & $29.5(26-42)$ & $28(26-35)$ & $\begin{array}{c}32.5 \\
(31.75-36.25)\end{array}$ & 0.315 & 0.259 & 0.776 & 0.153 \\
\hline \multicolumn{9}{|c|}{$\begin{array}{l}\text { Skin graft } \\
\text { engraftment time }\end{array}$} \\
\hline & Days & $14(13-20.25)$ & $14(14-21)$ & $\begin{array}{c}15.5 \\
(13.25-20)\end{array}$ & 0.583 & 0.295 & 0.837 & 0.844 \\
\hline \multicolumn{9}{|c|}{ Wound depth } \\
\hline & $\mathrm{Cm}$ & $0.5(0.5-1)$ & $0.8(0.5-1)$ & $0.5(0.5-0.62)$ & 0.299 & 0.150 & 0.923 & 0.374 \\
\hline \multicolumn{9}{|c|}{ Wound area } \\
\hline & $\mathrm{Cm}^{2}$ & $17(5.38-33.75)$ & $\begin{array}{c}20.5 \\
(11.12-44.5) \\
\end{array}$ & $\begin{array}{c}18.3 \\
(8.75-27) \\
\end{array}$ & 0.239 & 0.097 & 0.707 & 0.561 \\
\hline
\end{tabular}

Variable: Analysed variable; Level: Variables' level; Distribution: Count (\%) or median $\left(25^{\text {th }}-75^{\text {th }}\right.$ percentiles $)$ by substitute's type; Comparisons: $P$ values from the comparison among the substitute's types or from the pairwise comparison between specific substitute's types; *: $P$ value<0.05

therefore, provides low invasive and biologically effective procedures in the so-called fragile patient. Furthermore, not only clinical but also possible economic advantages in choosing dermal substitutes may exist, as surgical costs and surgical time are lower than in traditional reconstructive procedures. ${ }^{[10]}$

The use of dermal substitutes was sporadic and prudent in the early phase of our experience but as our confidence with both the procedures and the indications improved it was progressively included within the Unit's routine. Our experience with Nevelia ${ }^{\circledR}$ is limited because it has been in use in our Unit since 1 year only [Figure 1].

A split thickness skin graft transfer was performed after an average time of 28 days after the application of the dermal substitute, and there was no statistically significant difference among the different substitutes.
Such an outcome demonstrates similar biological integration times for all of the substitutes under study.

The engraftment time for a skin graft did not show significant differences amongst the different dermal substitutes, thus confirming in all of them the same fitness for supplying an autologous graft.

A very broad wound area range (range: $1.7-1400 \mathrm{~cm}^{2}$ ) was also observed in our sample and no correlation was demonstrated between the wound size and the choice of any specific dermal substitute. Such a figure confirms the extreme versatility of all of the dermal substitutes under study and their fitness for any wound size.

The statistical analysis demonstrated a correlation between the elective choice of Hyalomatrix ${ }^{\circledR}$ in the soft-tissue defects of the scalp following a radical excision 
of skin tumours that included either the periosteum only or the periosteum plus the outer table of the calvarium.

Although the engraftment of a skin graft can successfully take place on the exposed trabecular bone, its long-term outcome is generally poor due to the high risk of ulceration following minimal trauma. Therefore, the preliminary hyaluronan induced regeneration of a derma-like layer before skin graft transfer on the exposed diploe allowed for a thicker and more reliable bioengineered skin cover [Figure 4].

On the other hand, a skin graft on the bare bone is unlikely if not impossible. Here, the preliminary cover with a hyaluronan three-dimensional scaffold constantly allowed for the regeneration of a derma-like layer with a rich vascular network fit for supporting a split-thickness skin graft. In such a circumstance the revascularisation likely took place both from the periphery and from the fine capillaries lying in the inner and outer tables of the adult cranium thus allowing the integration of the substitute in broad areas of exposed bone, too ${ }^{[11]}$ [Figure 5].

Hyalomatrix ${ }^{\circledR}$ is a dermal substitute made of a non-woven pad of hyaluronic acid benzyl ester layered on top by a semi-permeable membrane of silicone. Hyaluronan provides hydration and maintenance of the extracellular space in the skin. It establishes complex interactions with matrix components and cells and its role ranges from a purely structural function to the regulation of cellular development. Hyaluronan also plays a relevant biological role in the process of wound healing ${ }^{[12]}$ by creating a favourable environment for cell migration. Furthermore,

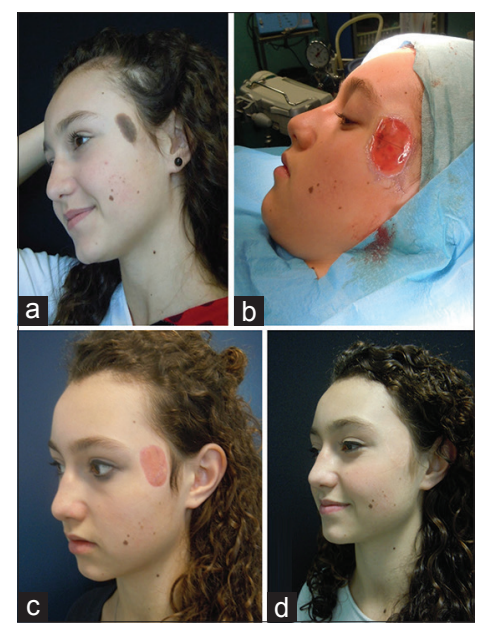

Figure 3: (a) Congenital melanocytic naevus of the right temple. (b) Temporary repair with Integra ${ }^{\circledR}$ dermal substitute following radical excision. (c) Stable repair following early engraftment of a split thickness skin graft.

(d) Long-term outcome of stable split thickness skin graft it provides protection against free radical and proteolytic damage to both cells and extracellular matrix molecules, due to its free-radical scavenging, protein-exclusion properties and antioxidant effect. ${ }^{[13-15]}$ In a previous study of ours ${ }^{[9]}$ Hyalomatrix $^{\circledR}$ derived bioengineered skin electively demonstrated to closely approach the hydration and transepidermal water loss of normal skin. Such a figure was supposed to be related to both a hyaluronan induced stimulation and regulation of the sweat gland remnants and a better epidermis-matrix interaction. It also revealed a lively hyaluronan induced neoangiogenesis. Therefore, Hyalomatrix ${ }^{\circledR}$ would be the most appropriate dermal substitute when the water regulation-related skin features and the neoangiogenetic boost are relevant issues.

Due to the limited size of our sample, the statistical analysis failed to reveal any further correlation between the choice of a specific dermal substitute and the remaining clinical variables. Nevertheless, we still prefer Hyalomatrix ${ }^{\circledR}$ when a faster wound healing is required, especially in the management of deep wounds where the priority is a fast obliteration with a new formed tissue provided with a rich blood supply [Figure 6] and Integra ${ }^{\circledR}$ when the goal is a better cosmetic and functional outcome, especially in visible areas of the face as there is no donor site scarring and morbidity [Figure 7]. However, these indications in our clinical practice still are anecdotally based.

Integra $^{\circledR}$ is a matrix of fibres of crosslinked bovine tendon collagen and a glycosaminoglycan (GAG;

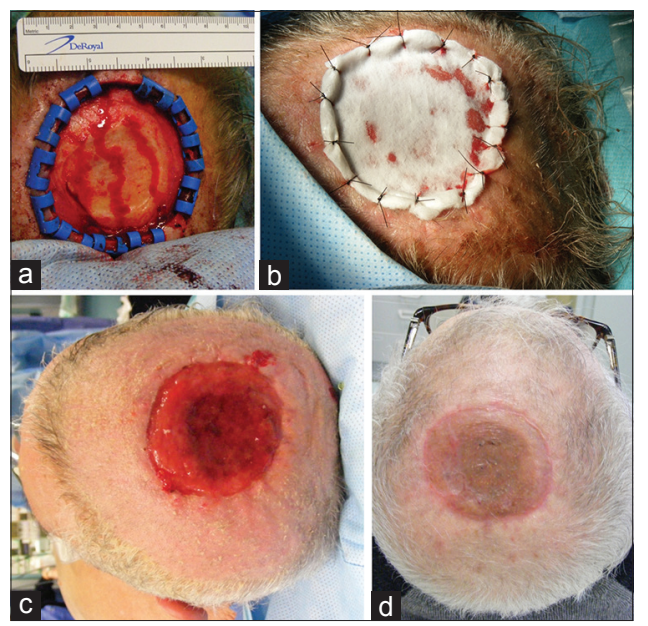

Figure 4: (a) Soft tissue loss following radical excision of locally infiltrating basal cell carcinoma of the vertex of the scalp. The defect includes the periosteum and a portion of the outer cortex of the skull bone. (b) The defect is temporarily repaired with Hyalomatrix ${ }^{\circledR}$ dermal substitute. (c) Regeneration of a derma-like layer with a rich vascular network fit for supporting a split-thickness skin graft. (d) Stable repair with a split thickness skin graft 


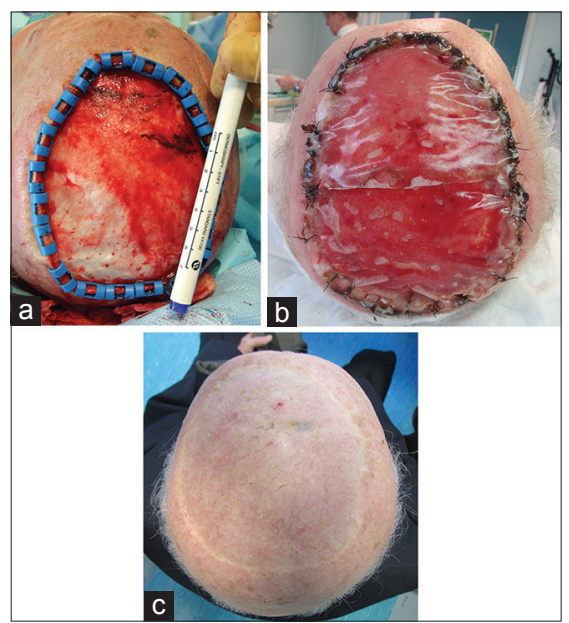

Figure 5: (a) Soft tissue loss following radical excision of locally infiltrating squamous cell carcinoma of the vertex of the scalp. The defect includes the periosteum in the lower left area of the excision. (b) Regeneration of a derma-like layer with a rich vascular network fit for supporting a split-thickness skin graft. (c) Long-term outcome after repair with a split-thickness skin graft. A minor area of instability is appreciated

chondroitin 6-sulphate) derived from shark cartilage covered on top by a silicone semi-permeable membrane. The bovine collagen and GAG serve as a template for the infiltration of fibroblasts, macrophages, lymphocytes and for the regeneration of a new vascular network. The host fibroblasts provide deposition of newly formed collagen and elastic fibres, which progressively replace the native bovine collagen and GAG three-dimensional scaffold. ${ }^{[16]}$ The silicone layer mimics the natural epidermis in providing adequate moisture control. Histological animal and human studies demonstrated good tissue compatibility and integrity, controlled biodegradation and no adverse immunological reactions. ${ }^{[17]}$ In a previous study of ours $^{[9]}$ Integra $^{\circledR}$ derived bioengineered skin electively demonstrated physical, mechanical and optical properties that best approximate to normal skin. Such a figure is likely to be related to its dermal structural organisation, which more closely resembles that of normal skin.

Therefore, Integra ${ }^{\circledR}$ should be the most appropriate solution when the best possible skin color and texture match is required.

Nevelia ${ }^{\circledR}$ was recently introduced in our clinical practice to broaden the spectrum of therapeutical options within the field of bioengineered skin repair.

Nevelia ${ }^{\circledR}$ is a novel three-dimensional porous matrix of stabilised bovine origin type I collagen covered on top by a semi-permeable membrane of silicone. It is made of

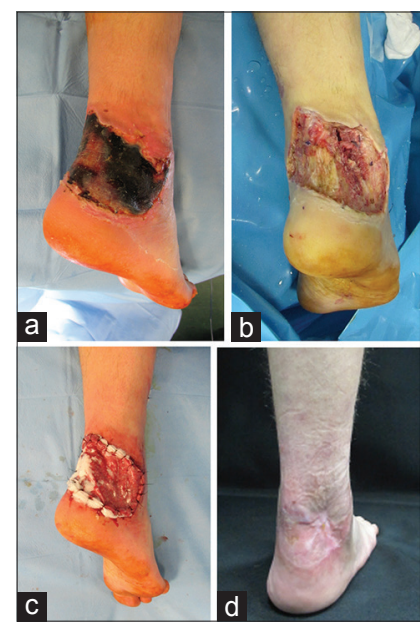

Figure 6: (a) Post-traumatic degloving injury of the Achilles region in the right foot. (b) Soft tissue loss following the wound debridement. (c) The defect is temporarily repaired with Hyalomatrix ${ }^{\circledR}$ dermal substitute. (d) Stable repair with a split-thickness skin graft

a specific native collagen with a large fibrous proportion to keep cell adhesion signals and mechanical structure to support regeneration. In vitro tests reveal an optimised fibroblast colonisation due to the recognition of collagen fibres and a fast initiation of the revascularisation

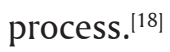

Although our preliminary results with the Nevelia ${ }^{\circledR}$ induced bioengineered skin would appear to be good, it is too short a clinical experience to make a long-term assessment on a large sample of cases and to identify its most appropriate clinical indications.

The most relevant complication in our sample was the melting graft syndrome that occurred in three cases of Hyalomatrix ${ }^{\circledR}$ skin reconstruction, two in the scalp and one in the gluteal area. Such a figure was related to the poor patients' compliance in the scalp reconstruction and to the objectively difficult management of the gluteal area. One scalp skin reconstruction had to undergo a second skin graft transfer while the other two cases eventually healed with spontaneous re-epithelisation from the wound margins after a course of advanced dressing. Indeed, in potentially contaminated devascularised wounds, and in large areas of bare bone autologous tissue transfer still is an appropriate indication as the bioengineered skin is particularly prone to infection due to the lack of skin adnexa.

In six cases, the bioengineered skin reconstruction could not be completed by a skin graft transfer because severe comorbidities contraindicated any further 


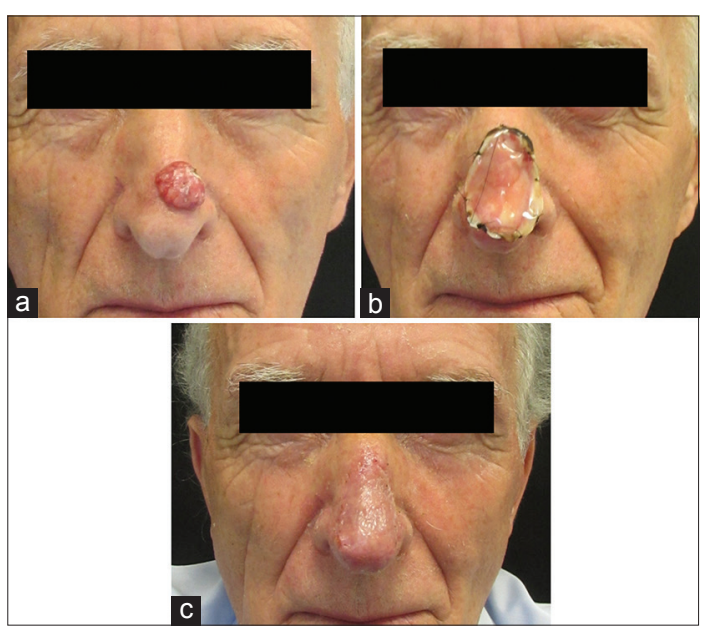

Figure 7: (a) Basal cell carcinoma of the dorsum of the nose. (b) Temporary repair with Integra ${ }^{\circledR}$ dermal substitute following tumour radical excision.

(c) Stable repair with a split thickness skin graft

surgical procedure. These cases eventually healed with re-epithelisation from the wound margins after a course of advanced dressing in a time ranging from 10 to 18 weeks.

\section{CONCLUSIONS}

In our experience, the dermal substitutes were essential and highly versatile reconstructive options providing effective solutions in a wide number of clinical problems with a significant reduction of the surgical complexity.

In our opinion, a hyaluronan-based dermal substitute is the most appropriate choice for coverage of exposed bone without periosteum and for deep soft tissue loss when a fast obliteration of deep dead space is the primary goal.

Similarly, a dermal substitute with a structured three-dimensional connective fibre organisation is the most appropriate indication when skin color and texture match is a relevant issue in specific clinical cases. Our both experimental ${ }^{[9]}$ and clinical results would suggest a relevant role for the dermal substitute in the modern reconstructive ladder. ${ }^{[19]}$

Nevertheless, we still need the dermal substitute of the future designed to integrate the demonstrated properties and advantages of both hyaluronan-based and collagen and GAG based scaffold to get cell, and extracellular matrix regulation joined to stimulation of the regenerative process with the establishment of a natural dermal fibres organisation.

\section{Financial support and sponsorship}

Nil.

\section{Conflicts of interest}

There are no conflicts of interest.

\section{REFERENCES}

1. Wolter TP, Noah EM, Pallua N. The use of integra in an upper extremity avulsion injury. Br J Plast Surg 2005;58:416-8.

2. Weigert R, Choughri H, Casoli V. Management of severe hand wounds with integra ${ }^{\circledR}$ dermal regeneration template. J Hand Surg Eur Vol 2011;36:185-93.

3. Heimbach D, Luterman A, Burke J, Cram A, Herndon D, Hunt J, et al. Artificial dermis for major burns. A multi-center randomized clinical trial. Ann Surg 1988;208:313-20.

4. Groos N, Guillot M, Zilliox R, Braye FM. Use of an artificial dermis (Integra) for the reconstruction of extensive burn scars in children. About 22 grafts. Eur J Pediatr Surg 2005;15:187-92.

5. Gravante G, Delogu D, Giordan N, Morano G, Montone A, Esposito G, et al. The use of hyalomatrix PA in the treatment of deep partial-thickness burns. J Burn Care Res 2007;28:269-74.

6. Motolese A, Vignati F, Brambilla R, Cerati M, Passi A. Interaction between a regenerative matrix and wound bed in nonhealing ulcers: Results with 16 cases. Biomed Res Int 2013;2013:849321.

7. Nicoletti G, Scevola S, Faga A. Bioengineered skin for aesthetic reconstruction of the tip of the nose: A case report. Dermatol Surg 2008;34:1283-7.

8. Faga A, Nicoletti G, Brenta F, Scevola S, Abatangelo G, Brun P, et al. Hyaluronic acid three-dimensional scaffold for surgical revision of retracting scars: A human experimental study. Int Wound J 2013;10:329-35.

9. Nicoletti G, Brenta F, Bleve M, Pellegatta T, Malovini A, Faga $A$, et al. Long-term in vivo assessment of bioengineered skin substitutes: A clinical study. J Tissue Eng Regen Med 2015;9:460-8.

10. Morozzo U, Villafañe JH, leropoli G, Zompi SC, Cleland JA, Navissano $M$, et al. Soft tissue reconstructions with dermal substitutes versus alternative approaches in patients with traumatic complex wounds. Indian J Surg 2015;77:1180-6.

11. Brookes M, Revell WJ. Blood supply of flat bones. Bones of the skull. In: Brookes M, Revell WJ, editors. Blood Supply of Bone. Scientific Aspects. London: Springer Verlag; 1998. p. 66.

12. Chen WY, Abatangelo G. Functions of hyaluronan in wound repair. Wound Repair Regen 1999;7:79-89.

13. Presti $D$, Scott JE. Hyaluronan-mediated protective effect against cell damage caused by enzymatically produced hydroxyl $(\mathrm{OH}$.) radicals is dependent on hyaluronan molecular mass. Cell Biochem Funct 1994;12:281-8.

14. Kvam BJ, Fragonas E, Degrassi A, Kvam C, Matulova M, Pollesello $P$, et al. Oxygen-derived free radical (ODFR) action on hyaluronan (HA), on two HA ester derivatives, and on the metabolism of articular chondrocytes. Exp Cell Res 1995;218:79-86.

15. Fukuda K, Takayama M, Ueno M, Oh M, Asada S, Kumano F, et al. Hyaluronic acid inhibits interleukin-1-induced superoxide anion in bovine chondrocytes. Inflamm Res 1997;46:114-7.

16. Wang H, Pieper J, Péters F, van Blitterswijk CA, Lamme EN. 
Synthetic scaffold morphology controls human dermal connective tissue formation. J Biomed Mater Res A 2005;74:523-32.

17. Michaeli $D$, McPherson M. Immunologic study of artificial skin used in the treatment of thermal injuries. J Burn Care Rehabil 1990;11:21-6.

18. Philandrianos C, Andrac-Meyer L, Mordon S, Feuerstein JM,
Sabatier F, Veran J, et al. Comparison of five dermal substitutes in full-thickness skin wound healing in a porcine model. Burns 2012;38:820-9.

19. Janis JE, Kwon RK, Attinger CE. The new reconstructive ladder: Modifications to the traditional model. Plast Reconstr Surg 2011;127 Suppl 1:205S-12S. 